\title{
DEPRESSION AND ANXIETY IN CORRELATION TO BODY AREAS INVOLVED IN PATIENTS OF BURNS
}

\author{
Ghazanfar Ali, Sikander Ali Khan, Muzzafar Ahmed, Muhammad Sheraz Afza Malik*, Danish Almas**, Abdul Majid \\ Combine Military Hospital Multan/National University Medical Sciences (NUMS) Pakistan, *Combine Military Hospital Quetta/National University Medical \\ Sciences (NUMS) Pakistan, ${ }^{* *}$ Combine Military Hospital Bahawalpur/National University of Medical University (NUMS) Pakistan
}

\section{ABSTRACT}

Objective: To evaluate the severity of depression and anxiety among patients of burns and correlate depression and anxiety with areas of body involved in burns.

Study Design: A cross-sectional study.

Place and Duration of Study: The departments of Psychiatry and department of Plastic Surgery, Combined Military Hospital Multan, from Oct 2019 to Mar 2020.

Methodology: Through consecutive sampling, 56 patients of burns reporting to burns unit were assessed for anxiety and/ or depression based on the diagnostic criteria of International Classification of Diseases version 10. Symptom severity was assessed using Beck Depressive Inventory for depression and Beck Anxiety Inventory for anxiety. Descriptive statistics like mean with standard deviation was calculated for age. Frequency along with percentages was calculated for sociodemographic variables, Anxiety and depression.

Results: Depression was present among 30 (53\%) of participants out of which $16(53.5 \%)$ had mild, 11 (37.9\%) had moderate while only $3(12.5 \%)$ had severe depression. Anxiety was seen among $50(89 \%)$ of participants out of which sixteen $(32.1 \%)$ had mild, $26(51.7 \%)$ had moderate while $8(16 \%)$ had severe anxiety. Significant correlation existed among the major area involved in burn with both anxiety and depression $(p<0.01)$.

Conclusion: There is a very high prevalence of anxiety and depression among patients of burn. Significant positive correlation existed between the level of anxiety and the areas involved in burns.

Keywords: Anxiety, Burns, Depression.

This is an Open Access article distributed under the terms of the Creative Commons Attribution License (https://creativecommons.org/licenses/by-nc/4.0/), which permits unrestricted use, distribution, and reproduction in any medium, provided the original work is properly cited.

\section{INTRODUCTION}

Burn care is among the few areas of medicine which are challenging medically, surgically and psychiatrically ${ }^{1-2}$. Psychological aspects are much more prevalent than these are estimated. The vulnerable people include the patients, their caregivers and medics $^{3-4}$. Although no one is immune to burn injury, the Bum injuries commonly affect the very young and the very old, both men and women ${ }^{1}$. Bum injuries are not same in all patients. These can vary from small wounds to extensive injuries. The former can be easily managed in the outpatient clinic while later require hospitalization for variable duration and multiple specialists and departments are in involved in provision of healthcare to the victims of severe burn injuries. It can result in multi-organ system failure, a prolonged hospital course, and long-term functional and psychosocial sequale ${ }^{5,6}$.

There is improved outcome of burn patients due to Improvements in resuscitation, the introduction of topical antimicrobial agents, and, most importantly,

Correspondence: Dr Ghazanfar Ali, Plastic Surgeon, Combined Military Hospital, Multan Pakistan

Received: 08 Apr 2020; revised received: 06 Aug 2020; accepted: 28 Aug 2020 the practice of early burn wound. However, the psychiatric aspects of the management of the burn patients have been under-rated. So this important aspect of burn management needs to be highlighted appropriately 7,8 .

It is not only the patient od severe burn who is vulnerable to various psychiatric disorders but People involved in looking after and treatment of severe burn patients are also prone to psychological stress and various other psychiatric ailments. This is because of physical, financial and emotional stress faced by them. The situation is further complicated and aggravated if the burn patient is the main earning person ${ }^{9,10}$.

A study was planned to assess and quantify the psychological impact of severe burn injuries. This can help in early detection of any psychiatric illness and appropriate management.

\section{METHODOLOGY}

This cross-sectional study was conducted at the department of Psychiatry, Combined Military Hospital March Multan in liaison with the department of Plastic Surgery from October 2019 to March 2020. A sample size of 56 was estimated via Epi Tools Epidemiological Calculator while keeping level of significance $5 \%$, 
confidence level 95\% estimated true proportion $79 \%$ 7 , and $11 \%$ of absolute precision ${ }^{11,12}$. We consecutively sampled 56 burn patients who were assessed for anxiety and/or depression based on the diagnostic criteria of International Classification of Diseases version 10 after approval from the hospital ethical committee. Patients having past history of psychiatric illness were excluded because their results may alter the findings of the research. All participants were interviewed after the informed written consent and their confidentiality was ensured. Individuals with other disabling diseases and past psychiatric history were not included.

Demographic details of the Participants inductees were documented. Burn related information included extent of burn (total body surface area involved), localized and reason of burn was noted.

Detailed assessment and symptom severity was assessed using beck depressive inventory (BDI) for depression and Beck Anxiety Inventory (BAI) for anxiety. BDI consists of 21 questions, each with four possible answers that are assigned a score ranging from 0-3. Higher scores indicate more severe symptoms. Total score is obtained by adding individual scores of 21 items and total score ranges from 0-63. The cut off score for presence of symptoms is ${ }^{9}$. It may be noted that BDI is for detecting depressive symptoms and not for diagnosing depression. Scores of 0-9 indicate minimal depression, 10-18 mild depression, 19-29 moderate depression, and scores of 30-63 indicate severe depressive symptoms. BAI consists of 21 items, scored on Likert-type scale from 0-3 where 0 is considered negative, 1 is judged as mild, 2 is deemed moderate, and 3 is considered severe. Total score of 0-7 reflects minimal anxiety and a score of 8-15 points toward mild anxiety. Score of 16-25 correlates with moderate anxiety and score of 26-63 compares with severe anxiety. Descriptive statistics like mean with standard deviation was calculated for age. Frequency along with percentages was calculated for socio-demographic variables. Frequency and proportions were also calculated for extent of depression and anxiety in burn patients.

Data analysis was performed using SPSS-20. The data were described as num-bers and percentages. For association and comparison Pearson's Chi square test was used. All the inferences were made at $95 \%$ confidence interval and $p$-values of $\leq 0.05$ were considered significant.

\section{RESULTS}

Fifty six participants were included in this study. Forty $(71.4 \%)$ participants were male while 16 (38.5\%) were female. Thirty seven (65\%) of participants ranged between 15-40 years of age while 19 (35\%) ranged between 41-60 years of age. Mean age of participants was $32.3 \pm 18$ years. Forty three $(76 \%)$ participants were married while 13 (23.2\%) were unmarried. Twenty six (46.4\%) participants were primary educated, 18 (32.1\%) secondary educated, $9(16 \%)$ had higher education, $2(3.5 \%)$ were graduate while $1(1.7 \%)$ was illiterate. Forty $(71.4 \%)$ participants were employed while 16 (28.5\%) were unemployed (table-I).

Burn injuries on multiple sites was seen in 22

Table-I: Distribution of demographic variables.

\begin{tabular}{|c|c|}
\hline Characteristics & n (\%) \\
\hline \multicolumn{2}{|l|}{ Age } \\
\hline $15-40$ & $37(65)$ \\
\hline $41-60$ & $19(35)$ \\
\hline \multicolumn{2}{|l|}{ Gender } \\
\hline Male & 40 (71.4) \\
\hline Female & $16(28.5)$ \\
\hline \multicolumn{2}{|l|}{ Marital Status } \\
\hline Married & $43(76)$ \\
\hline Unmarried & $13(23.2)$ \\
\hline \multicolumn{2}{|c|}{ Educational Status of the Patient } \\
\hline Illiterate & $1(1.7)$ \\
\hline Primary & $26(46.4)$ \\
\hline Secondary & $18(32.1)$ \\
\hline High school & $9(16)$ \\
\hline University & $2(3.5)$ \\
\hline \multicolumn{2}{|c|}{ Employment Status of the Patient } \\
\hline Employed & 40 (71.4) \\
\hline Un-employed & $16(28.5)$ \\
\hline \multicolumn{2}{|l|}{ Major Area Involved } \\
\hline Head neck and face & $7(12.5)$ \\
\hline Trunk & $3(5.3)$ \\
\hline Arms and hands & 19 (33.9) \\
\hline Legs and feet & $5(8.9)$ \\
\hline Multiple sites & $22(39.2)$ \\
\hline \multicolumn{2}{|c|}{ Total Body Surface Area Involved } \\
\hline Up to $25 \%$ & 47 (83.9) \\
\hline More than $25 \%$ & $9(16)$ \\
\hline \multicolumn{2}{|c|}{ Reason for Burn Injury } \\
\hline Flame & 29 (51.7) \\
\hline Chemical & $3(5.3)$ \\
\hline Electric & $3(5.3)$ \\
\hline Explosive & $2(3.5)$ \\
\hline Scald & $19(33.9)$ \\
\hline \multicolumn{2}{|l|}{ Level of Anxiety } \\
\hline Mild & $16(32.1)$ \\
\hline Moderate & $26(51.7)$ \\
\hline Severe & $8(16)$ \\
\hline \multicolumn{2}{|l|}{ Level of Depression } \\
\hline Mild & $16(53.5)$ \\
\hline Moderate & $11(33.9)$ \\
\hline Severe & $3(12.5)$ \\
\hline
\end{tabular}


(39.25), injury to arms and hands in 19 (33.9\%), head, face and neck in 7 (12.5\%), legs and feet burn injuries in $5(8.9 \%)$ while only $3(5.3 \%)$ sustained burn injuries on trunk (table-I).

Majority of participants i.e. $47(83.9 \%)$ sustained up to $25 \%$ of burn injury while $9(16 \%)$ of participants sustained $>25 \%$ of burn injury. Flame injury affected $29(51.7 \%)$, scald affected 19 (33.9\%), 3 (5.3\%) each for chemical and electric burn injuries while only $2(3.5 \%)$ were affected by burns due to explosives (table-I).

Depression was present among $30(53 \%)$ of participants out of which 16 (53.5\%) had mild, 11 (37.9\%) had moderate while only $3(12.5 \%)$ had severe depression (table-I). Twenty six (55.5\%) participants with burn injuries up to $25 \%$ had depression. Six (66.6\%) participants having burn injuries of $>25 \%$ presented with depression (table-II).

Table-II: Anxiety and depression in burn patients with relation to body surface area.

\begin{tabular}{|c|c|c|}
\hline $\begin{array}{l}\text { Factors } \\
\text { n }(\%)\end{array}$ & $\begin{array}{c}\text { Depressed } \\
\text { n }(\%)\end{array}$ & $\begin{array}{l}\text { Anxiety } \\
\text { n (\%) }\end{array}$ \\
\hline \multicolumn{3}{|l|}{ Total Body Surface Area } \\
\hline \multicolumn{3}{|l|}{ Involved (n) } \\
\hline Up to $25 \%(n=47)$ & $26(55.3)$ & $37(78.7)$ \\
\hline More than $25 \%(n=9)$ & $6(66.6)$ & $8(88.8)$ \\
\hline \multicolumn{3}{|l|}{ Major Area of Body } \\
\hline Head, neck and face $(n=7)$ & $3(57.1)$ & $6(85.7)$ \\
\hline Trunk $(n=3)$ & $2(66.6)$ & $3(100)$ \\
\hline Arms and hand $(n=19)$ & $10(57.8)$ & $17(89.4)$ \\
\hline Legs and feet $(n=5)$ & $1(20)$ & $4(60)$ \\
\hline Multiple sites $(n=22)$ & $14(72)$ & $20(90.9)$ \\
\hline \multicolumn{3}{|l|}{ Reason of Burns } \\
\hline Flame $(\mathrm{n}=29)$ & $23(79.3)$ & $26(89.6)$ \\
\hline Chemical $(n=3)$ & $1(33.3)$ & $3(100)$ \\
\hline Electric $(n=3)$ & $2(66.6)$ & $2(66.6)$ \\
\hline Explosive $(n=2)$ & $1(50)$ & $2(100)$ \\
\hline Scalds $(n=19)$ & $6(31.5)$ & $15(78.0)$ \\
\hline
\end{tabular}

$(79.3 \%)$ of those who sustained burn injuries from flames, $6(31.5 \%)$ having scald and $2(66.6 \%)$ of participants with electric burn injuries presented respectively with depression (table-II).

Anxiety was seen among 50 (89\%) of participants out of which $16(32.1 \%)$ had mild, $26(51.7 \%)$ had moderate while $8(16 \%)$ had severe anxiety (table-I). Thirty seven $(78.7 \%)$ participants who had burn injuries up to $25 \%$ presented with anxiety while only 8 $(88.8 \%)$ having burn injury of $>25 \%$ presented with anxiety. Twenty (90.9\%) participants with multiple burn injuries, 17 (89.4\%) having burn injuries on arms and hands, $6(85.7 \%)$ participants with head, neck and face burns, $4(60 \%)$ participants with burn injuries on leg and feet presented with anxiety (table-II).

Twenty six $(89.6 \%)$ participants with flame burn injuries, 15 (78.9\%) participants having scalds, $3(100 \%)$ having chemical burns, $2(100 \%)$ having burns due to explosions and $2(66.6 \%)$ of participants with electric burns presented respectively with anxiety (table-II). After evaluating statistical correlation of body areas involved in burns with the severity of anxiety and depression, a significant correlation was found with both anxiety and depression $(p=0.00)$ (table-III).

\section{DISCUSSION}

In this study $65 \%$ of the participants were between 15-40 years of age with mean age of 32.3. Proportion of males was $71.4 \%$ and $38.5 \%$ were females. $98 \%$ of participants were literate or educated while only $1.7 \%$ were illiterate. These results are similar to the results of study done by Alvi in which mean age of participants was $31.4,60 \%$ were male, $40 \%$ were females and $100 \%$ were educated 7 .

In this study $39.2 \%$ of the participants sustained burn injury to the multiple sites followed by injuries to

Table-III: Anxiety and depression in burn patients with relation to body areas involved.

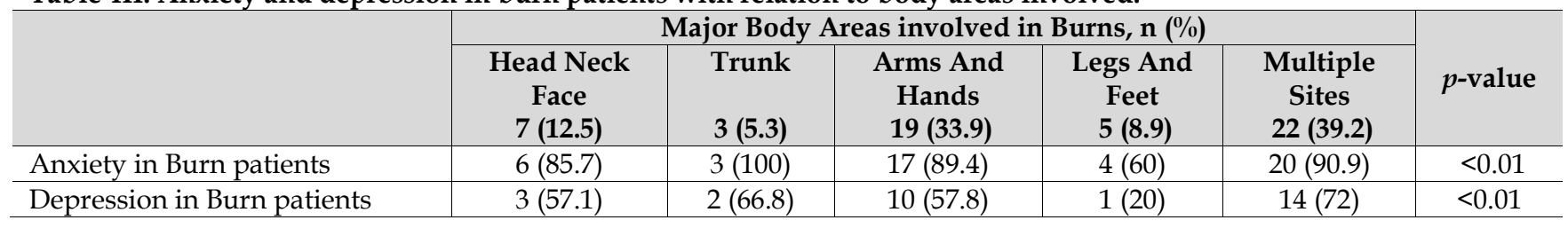

Fourteen $(72.7 \%)$ of participants with multiple site burn injuries presented with depression, $10(57.8 \%)$ of participants with arms and hand burn injury, 3 (57.1\%) of participants with head, neck and face burns while 2 (66.6\%) participants with burn injuries to trunk and 1 (20\%) of participants with burn injuries to leg and feet presented respectively with depression. Twenty three arms and hands in $33.9 \%$ while only $12,5 \%$ of participants sustained injuries to head neck and face as compared to the results of study done by Loncar that noted burn injuries to head and face in $53 \%$ of participants 13 . Results of this study are also different from the results of study by Alvi that shows burn injuries on multiple sites in $56 \%$ of participants, $16 \%$ burn injuries to head 
neck and face, $14 \%$ burn injuries to leg and feet while only $12 \%$ sustained burn injuries to arm and hand 7 .

In this study it is noted that in $83.9 \%$ of participants total body surface area involved in burn injury was up to $25 \%$ similar results are seen in study done by Fauerbach ${ }^{14}$, but these results are different from the result of study done by duke et al, that has shown that total body surface area involved in burn injury was up to $25 \%$ in $46 \%$ of participants ${ }^{15}$. On the contrary there is a study by Vetrichevvel et al, that has noted that in 59\% of participants the total body surface area involved after burn was $>25 \% 16$.

Burn injuries due to flame is seen in $51.7 \%$ and scalds in $33.9 \%$ of participants. Similar results were seen in study done by Alvi in which $78.9 \%$ of burn injuries were due to flame injuries, $71 \%$ had electric burns as compared to $5 \%$ in this study, $46.1 \%$ of participants sustained burn injuries due to bomb blast as compared to $3 \%$ of participants in this study but only $25 \%$ of participants of their study had scalds 7 .

Duke et al, in his study has noted that $32.6 \%$ develop anxiety after burn injuries while $27.8 \%$ develop depression ${ }^{15}$. Alvi in her study reported that $82 \%$ of individuals with burn injuries develop anxiety while $58 \%$ individuals with burn injuries develop depression? In this study $89 \%$ of participants developed anxiety after burn injuries, out of which $51 \%$ had moderate, $32 \%$ had mild and only $8 \%$ had severe anxiety as compared to the results of study done by Alvi in which $22 \%$ had moderate, $28 \%$ had mild while $34 \%$ of individuals had severe level of anxiety ${ }^{7}$. Similar results of study by Loncar show that $24 \%$ had moderate anxiety, $67 \%$ had mild while only $8 \%$ of individuals with burn injuries develop severe anxiety ${ }^{13}$.

Wiechman has noted that $43 \%$ of individuals with burn injuries develop moderate to severe depression ${ }^{17}$. Similarly Dalal and Manu noted that $48 \%$ of individual with burn injuries develop moderate to severe depres$\operatorname{sion}^{18}$. Fauerbach notes that $54 \%$ of individuals with burn injuries develop anxiety while $28 \%$ develop depression ${ }^{14}$. According to Loncar $49 \%$ of individuals with burn injuries develop depression out of which $20 \%$ had mild depression, $21 \%$ had moderate depression while $7 \%$ had severe level of depression ${ }^{13}$. Alvi has noted that $58 \%$ of individuals with burn injuries develop depression out of which $28 \%$ had mild level of depression, $14 \%$ had moderate while $18 \%$ had severe level of depression 7 . In this study $53 \%$ of individuals with burn injuries developed depression out of which $53.5 \%$ of participants had mild level of depression, $33.9 \%$ had moderate depression while only $12.5 \%$ of participants developed severe level of depression.

Significant correlation has been noted by Loncar between total body surface area involved due to burn injury and depression and anxiety ${ }^{13}$. In this study $55.3 \%$ of participants who had up to $25 \%$ of total body surface area involved after burn injury develop depression while $78.7 \%$ of participants developed anxiety.

Management of a patient with burn has always been challenging. There have been great achievements in management of burn patients with advancing technologies. With all these measures there has been significant reduction in both morbidity and mortality among the burn patients and they are returning early to their jobs. But all these measures take care of physical aspects of the injury and in developing countries like ours, the psychiatric aspect of burn injuries have been underrated. Mental health issues deserve special attention along with better understanding of the pathophysiology and systemic and local effects of burn on the body.

\section{RECOMMENDATION}

The management of burn patients should be based on team approach and early involvement of psychiatrist should be routine practice for detection and proper management of anxiety and depression in burn patients.

\section{CONCLUSION}

The burn patients have a very high prevalence of anxiety and depression. Studies have highlighted the importance of early detection and timely management of anxiety and depression in burn patients. This can only be done with close co-ordination among the various specialties involved in the management of this ailment. This further highlights the importance of coordinated multifaceted approach towards the burn management specially early involvement of psychiatrist should be routine practice for detection and proper management of anxiety and depression in burn patients.

\section{CONFLICT OF INTEREST}

This study has no conflict of interest to be declared by any author.

\section{REFERENCES}

1. Klein MB. Thermal, chemical, and electrical injuries. Grabb and Smith's Plastic Surg 2007: 132-49.

2. Wiechman SA, Ptacek JT, Patterson DR, Gibran NS, Engrav LE, Heimbach DM. Rates, trends, and severity of depression after burn injuries. J Burn Care Rehab 2001; 22(6): 417-24. 
3. Dalal PK, Saha R, Agarwal M. Psychiatric aspects of burn. Indian journal of plastic surgery: official publication of the Association of Plastic Surgeons of India. 2010; 43(Suppl-1): S136-40.

4. Atwell K, Bartley C, Cairns B, Charles A. Incidence of self-inflicted burn injury in patients with major psychiatric illness. Burns 2019; 45(3): 615-20.

5. Pallua N, Künsebeck HW, Noah EM. Psychosocial adjustments 5 years after burn injury. Burns 2003; 29(2): 143-52.

6. Thombs BD, Bresnick MG, Magyar-Russell G, Lawrence JW, Mc Cann UD, Fauerbach JA. Symptoms of depression predict change in physical health after burn injury. Burns 2007; 33(3): 292-98.

7. Alvi T, Assad F, Malik MA. Anxiety and depression in burn patients. J Ayub Med Coll 2009; 21(1): 137-41.

8. Bayuo J, Agyei FB, Baffour PK. Burns in the middle belt of Ghana: a systematic review. Burns Open 2018; 2(2): 85-89.

9. Agbenorku P, Aboah K, Akpaloo J, Amankwa R, Farhat B, Turkson $\mathrm{E}$, et al. Epidemiological studies of burn patients in a burn center in Ghana: any clues for prevention?. Burns Trauma 2016; 4(1): $1-4$.

10. Li S, Yaseen ZS, Kim HJ, Briggs J, Duffy M, Frechette-Hagan A, et al. Entrapment as a mediator of suicide crises. BMC Psychiatry 2018; 18(1): 4-6.

11. Qiuping LI, Yi LI, Yinghua XU, Huiya ZH. The impact of depression and anxiety on quality of life in Chinese cancer patientfamily caregiver dyads, a cross-sectional study. Health Quality
Life Outcomes 2018; 16(1): 230-35.

12. Logsetty S, Shamlou A, Gawaziuk JP, March J, Doupe M. Mental health outcomes of burn: a longitudinal population-based study of adults hospitalized for burns. Burns. 2016; 42(4): 738-44.

13. Lončar Z, Braš M, Mičković V. The relationships between burn pain, anxiety and depression. Collegium antropologicum. 2006; 30(2): 319-25.

14. Wiechman S, Kalpakjian CZ, Johnson KL. Measuring depression in adults with burn injury: A systematic review. J Burn Care Res 2016; 37(5): e415-26.

15. Duke JM, Randall SM, Vetrichevvel TP, Mc Garry S, Boyd JH, Rea $S$, et al. Long-term mental health outcomes after unintentional burns sustained during childhood: a retrospective cohort study. Burns Trauma 2018; 6(1): 1-10.

16. Vetrichevvel TP, Randall SM, Wood FM, Rea S, Boyd JH, Duke JM. A population-based comparison study of the mental health of patients with intentional and unintentional burns. Burns Trauma 2018; 6(1): 1-10.

17. Spronk I, Legemate CM, Dokter J, Van Loey NE, van Baar ME Polinder S. Predictors of health-related quality of life after burn injuries: a systematic review. Critical Care 2018; 22(1): 160-63.

18. Yurdalan SU, Ünlü B, Seyyah M, Şenyıldız B, Çetin YK, Çimen M. Effects of structured home-based exercise program on depression status and quality of life in burn patients. Burns 2018; 44(5): 1287-93. 